\title{
Barrett's esophagus and the risk of obstructive sleep apnea: a case-control study
}

Linda C Cummings ${ }^{1 *}$, Ninad Shah ${ }^{2}$ Santo Maimone ${ }^{3}$, Wajeeh Salah', Vijay Khiani ${ }^{4}$ and Amitabh Chak ${ }^{1}$

\begin{abstract}
Background: Prior studies suggest that obstructive sleep apnea may be associated with gastroesophageal reflux disease, a strong risk factor for Barrett's esophagus. The goals of this pilot case-control study were to determine whether Barrett's esophagus patients have an increased likelihood of obstructive sleep apnea and to determine whether nocturnal gastroesophageal reflux symptoms affect the relationship between Barrett's esophagus and obstructive sleep apnea risk.

Methods: Patients with Barrett's esophagus completed the Berlin Questionnaire, a validated survey instrument identifying subjects at high risk for obstructive sleep apnea. Two outpatient control groups were recruited: 1) EGD Group, subjects matched to Barrett's esophagus cases by age, race, and gender with esophagogastroduodenoscopy negative for Barrett's esophagus; and 2) Colonoscopy Group, patients getting colonoscopy. Rates of scoring at high risk for obstructive sleep apnea were compared. Respondents were also questioned regarding severity of their typical gastroesophageal reflux symptoms and presence of nocturnal gastroesophageal reflux symptoms.
\end{abstract}

Results: The study included 287 patients (54 Barrett's esophagus, 62 EGD, and 171 colonoscopy subjects). Barrett's esophagus patients were slightly older than colonoscopy patients and more obese. 56\% $(n=30)$ of Barrett's esophagus subjects scored at high risk for obstructive sleep apnea, compared with $42 \%(n=26)$ of $E G D$ subjects $(O R) 1.73,95 \% \mathrm{Cl}$ $[0.83,3.62])$ and $37 \%(n=64)$ of colonoscopy patients (OR 2.08, 95\% Cl $[1.12,3.88])$. The association between Barrett's esophagus and scoring at high risk for obstructive sleep apnea compared with colonoscopy patients disappeared after adjusting for age. Barrett's esophagus patients reported more severe typical heartburn and regurgitation symptoms than either control group. Among all subjects, patients with nocturnal reflux symptoms were more likely to score at high risk for obstructive sleep apnea than patients without nocturnal reflux.

Conclusions: In this pilot study, a high proportion of Barrett's esophagus subjects scored at high risk for obstructive sleep apnea. Having Barrett's esophagus was associated with more severe gastroesophageal reflux symptoms, and nocturnal reflux symptoms were associated with scoring at high risk for obstructive sleep apnea. The need for obstructive sleep apnea screening in Barrett's esophagus patients with nocturnal gastroesophageal reflux symptoms should be further evaluated.

Keywords: Barrett's esophagus, Gastroesophageal reflux disease, Obesity, Obstructive sleep apnea

\section{Background}

Esophageal adenocarcinoma (EAC) has dramatically increased in incidence in the United States over the last 3 decades $[1,2]$ and is strongly linked to its precursor metaplastic lesion, Barrett's esophagus (BE), and gastroesophageal reflux disease (GERD) [3]. Current guidelines recommend considering endoscopic screening of patients

\footnotetext{
* Correspondence: linda.cummings@case.edu

'Division of Gastroenterology and Liver Disease, Department of Medicine, University Hospitals Case Medical Center, 1100 Euclid Avenue Mailstop 5066, Cleveland, OH 44106-5066, USA

Full list of author information is available at the end of the article
}

with multiple risk factors for Barrett's esophagus including chronic GERD symptoms [4]. Studies suggest that 8\%-13\% of patients with GERD have BE [5,6], compared with a rate of $1 \%-6 \%$ in patients without heartburn symptoms [6,7]. The risk of BE increases with increasing duration of reflux symptoms, particularly nocturnal symptoms $[3,8]$. Moreover, GERD patients with BE typically have a greater duration of esophageal acid exposure than those without BE.

$\mathrm{BE}$ and esophageal adenocarcinoma are also associated with obesity [9-11]. The increase in obesity in the United States over the past several decades has been proposed as

\section{Biomed Central}


an explanation for the rising incidence of esophageal adenocarcinoma. Obesity and its associated health conditions represent a growing public health concern in the United States. Obesity-associated obstructive sleep apnea (OSA), for example, is an important albeit underdiagnosed syndrome with detrimental cardiovascular and neurocognitive effects. Like those at risk for BE, patients at risk for OSA are typically male, obese, and middle-aged.

Prior theory and evidence suggest that OSA is associated with gastroesophageal reflux disease. It has been theorized that negative intrapleural pressures generated during nocturnal airway obstruction in OSA could contribute to nocturnal gastroesophageal reflux [12,13], although studies have not demonstrated a direct relationship between obstructive events and nocturnal GERD events [12,14]. Alternatively, it is possible that obstructive events could lead to weakening at the lower esophageal sphincter over time [14]. A population-based study reported increased nocturnal GERD symptoms in patients with sleep-disordered breathing symptoms [15]. A large cohort study suggested that nocturnal GERD may be associated with increased body mass index and sleep complaints [16]. A study of 1093 OSA patients found that frequent nocturnal GERD was associated with more severe OSA, independent of body mass index [13]. Other studies have demonstrated that treatment of OSA with continuous positive airway pressure effectively treats nocturnal gastroesophageal reflux symptoms $[17,18]$. Continuous positive airway pressure treatment in OSA patients with GERD significantly reduced nocturnal acid contact time as measured by esophageal $\mathrm{pH}$ monitoring [18]. Metabolic changes associated with OSA including increased oxidative stress [19] and alteration in serum levels of insulin and insulin-like growth factors [20] could predispose to BE. The role of nocturnal reflux in Barrett's esophagus needs further investigation. Although some studies have suggested that nocturnal reflux symptoms are not associated with Barrett's esophagus among GERD patients [21,22], other studies have measured increased nocturnal esophageal acid exposure [23] or nocturnal non-acid reflux [24] in BE patients compared with GERD patients without BE.

Given the growing body of evidence associating OSA with gastroesophageal reflux disease, this pilot study aimed to determine whether patients with $\mathrm{BE}$ are more likely to be at risk for OSA. We hypothesized that BE patients would be more likely to score at high risk for OSA on a survey instrument for OSA screening compared with controls. We also aimed to determine if nocturnal gastroesophageal reflux symptoms affected the relationship between $\mathrm{BE}$ and high risk for OSA.

\section{Methods}

The study was approved by the University Hospitals Case Medical Center Institutional Review Board and was performed in accordance with the Declaration of Helsinki.
We performed a pilot case-control study comparing risk for OSA between subjects with Barrett's esophagus and 2 control groups. Risk for OSA was determined based on an addended version of the Berlin Questionnaire, a validated survey instrument used for OSA screening that identifies subjects at high risk for OSA $[25,26]$. Two control groups identified from patients undergoing outpatient endoscopy were recruited including patients from another study as previously described [27]: 1) Subjects matched to BE cases by age \pm 5 years, race, and gender with upper endoscopy negative for $\mathrm{BE}$ (hereafter referred to as the EGD group); and 2) Patients presenting for outpatient colonoscopy, including open-access cases, who had no prior upper endoscopy at our facility (hereafter referred to as the COL group). If possible, we matched up to $3 \mathrm{EGD}$ control subjects per $\mathrm{BE}$ case subject by age (at time of survey) \pm 5 years, race, and gender. The survey was distributed via mailings to BE patients who had previously undergone upper endoscopy and in person at the time of endoscopy. The vast majority of control subjects were recruited at the time of endoscopy, with 2 EGD control subjects completing their surveys $<14$ days after an upper endoscopy negative for BE. Informed consent was obtained from all subjects.

\section{Inclusion/exclusion criteria}

Barrett's esophagus cases included patients with a known diagnosis of histologically confirmed short-segment or long-segment Barrett's esophagus followed for surveillance in our endoscopy lab as well as incident BE cases diagnosed at the time of survey completion based on endoscopic and histological findings. An existing Barrett's esophagus database was used to identify potential cases. In addition, the results of a pathology database search for intestinal metaplasia were used in conjunction with endoscopy reports to identify potential cases; for these purposes, intestinal metaplasia had to be present on $\geq 1$ biopsy of salmon-colored mucosa from the distal esophagus. We excluded patients with a known diagnosis of obstructive sleep apnea because it was felt that the results of the Berlin Questionnaire might be difficult to interpret in OSA patients compliant with therapy; additionally, the control groups included a subset of patients from another study [27] in which those with OSA were excluded up front and therefore did not complete the Berlin Questionnaire. We excluded patients with esophageal adenocarcinoma, patients aged $<18$ years, those unable to give consent, and those unable to read or respond to survey questions. In addition, patients with malignancy with distant metastases or those with malignancy who had undergone radiation or chemotherapy within 1 year prior to the survey were excluded. Electronic medical records were reviewed for documentation of metastatic disease and radiation or chemotherapy treatment. Surveys were administered between September 2006 and May 2008. 


\section{Survey Instrument}

The Berlin Questionnaire (BQ) is a brief survey that has been validated as a means of identifying patients that are at risk for OSA [25]. This questionnaire asks about weight change, daytime sleepiness, snoring, and presence or absence of hypertension. Based on their responses, subjects are considered to be at high risk for OSA if they meet requirements for at least 2 of 3 symptom categories: 1) persistent symptoms ( $>3$ to 4 times/week) in 2 or more questions about snoring; 2 ) persistent ( $>3$ to 4 times/week) daytime somnolence and/or drowsiness while driving; and 3) body mass index (BMI) of more than 30 $\mathrm{kg} / \mathrm{m}^{2}$ (based on self-reported height and weight in this study) or history of high blood pressure. In a primary care setting, being identified by the Berlin Questionnaire to be at high risk for OSA predicted a respiratory disturbance index (RDI) greater than 5 with a sensitivity of 0.86 , a specificity of 0.77 , a positive predictive value of 0.89 , and a likelihood ratio of 3.79 [25]. The Berlin Questionnaire has also been validated in surgical patients [28].

To better assess risk factors, the Berlin Questionnaire was addended with standardized questions regarding the severity of the subject's typical GERD symptoms (see subsection Summary of Modified Berlin Questionnaire) and presence of nocturnal regurgitation and heartburn. Heartburn or regurgitation symptoms were considered present if the respondent rated his/her usual heartburn or acid regurgitation symptoms as at least mild in severity. Severe heartburn or acid regurgitation symptoms were defined as lifestyle-affecting. Nocturnal gastroesophageal reflux symptoms were considered present if the respondent reported that heartburn or acid regurgitation had awakened him/her in the past year. Nocturnal regurgitation was imputed as absent for $1 \mathrm{COL}$ patient who did not answer the question regarding awakening by nocturnal regurgitation in the past year, but rated his usual acid regurgitation symptoms as nonexistent.

\section{Summary of Modified Berlin Questionnaire}

A summary of the modified Berlin Questionnaire used in the study, including the Berlin Questionnaire and its scoring system and additional questions regarding gastroesophageal reflux disease symptoms, is presented below.

Subjects were considered to be at high risk for obstructive sleep apnea if $\geq 2$ of 3 symptom categories were positive. Categories 1 and 2 were considered positive if the patient answered yes to $\geq 2$ questions, and Category 3 was considered positive if the patient answered yes to $\geq 1$ question.

\section{Category 1: Snoring}

- Does the patient snore?

- Does the patient snore $\geq 3-4$ times per week?
- Does the patient stop breathing while sleeping $\geq 3-4$ times per week?

- Is the patient's snoring at least louder than talking?

- Does the snoring bother other people?

\section{Category 2: Daytime Somnolence}

- Does the patient feel tired after sleeping $\geq 3-4$ times per week?

- Does the patient feel tired during waketime $\geq 3-4$ times per week?

- Has the patient ever fallen asleep while driving?

- Does falling asleep while driving occur $\geq 3-4$ times per week?

\section{Category 3: Obesity/Hypertension}

- Does the patient have high blood pressure?

- Does the patient have a body mass index $>30$ ? (Based on self-reported height and weight)

\section{Questions regarding Gastroesophageal Reflux Disease}

\section{Questions about heartburn}

- Severity rating of the patient's typical heartburn (nonexistent, mild, moderate, or severe)

- Has heartburn awakened the patient at night in the past year?

\section{Questions about acid regurgitation}

- Severity rating of the patient's typical acid regurgitation (nonexistent, mild, moderate, or severe)

- Has acid regurgitation awakened the patient at night in the past year?

\section{Power calculation/Study population}

We anticipated based on our population of approximately $150 \mathrm{BE}$ patients that are regularly followed at our Digestive Health Institute and an expected survey response rate of $50 \%$ that we would be able to capture $75 \mathrm{BE}$ cases. Prior studies in the United States using the Berlin Questionnaire in primary care settings and a cardiology referral clinic found that $32 \%-36 \%$ of subjects were identified as being at high risk for OSA [26,29]. Assuming a $35 \%$ prevalence of being at high risk for OSA (hereafter referred to as $\mathrm{BQ}+$ ) in the control group and a $55 \%$ prevalence of being $\mathrm{BQ}+$ in our case group, our study would have $83 \%$ power to detect this difference at $\alpha=0.05$. Of note, our study findings were consistent with the incidences arrived at in our power calculation. This calculation did not account for matching, which should increase the power of the study.

We recruited 73 Barrett's esophagus cases and 242 controls, of which 66 were in the EGD group and 176 were in the COL group. The final comparison groups were 
comprised of 54 Barrett's esophagus cases, 62 EGD control patients, and $171 \mathrm{COL}$ control patients after the following exclusions: $6 \mathrm{BE}$ cases with esophageal adenocarcinoma; 4 subjects with recent chemotherapy or radiation for malignancy (1 BE case, 2 EGD patients, and 1 COL patient); 4 COL patients with metastatic disease; $11 \mathrm{BE}$ cases previously diagnosed with OSA $(\mathrm{n}=10)$ or missing OSA status $(\mathrm{n}=1) ; 2$ EGD patients previously diagnosed with OSA; and 1 patient with missing case status.

\section{Statistical considerations}

Descriptive statistics were performed on baseline characteristics. Continuous variables were compared between control and case groups using t-tests. Categorical variables were compared between control and case groups using chi-square tests or Fisher's exact test where appropriate. Covariates that significantly differed between the $\mathrm{COL}$ and $\mathrm{BE}$ groups were evaluated further using a univariate logistic regression model to identify predictors of scoring at high risk for OSA on the Berlin Questionnaire. A multivariate logistic regression model was developed including covariates that were significant predictors in univariate models by the likelihood ratio test. Data were analyzed using SAS (9.2 for Windows, SAS Institute Inc., Cary, North Carolina, USA).

\section{Sensitivity Analysis}

To account for possible misclassification of Barrett's esophagus patients as controls in the COL group, a sensitivity analysis was performed assuming a $7 \%$ rate of misclassification based on prior literature [6]. The odds ratio describing the association between $\mathrm{BE}$ and being $\mathrm{BQ}+$ was calculated based on different assumptions regarding the $\mathrm{BQ}+$ rate among these misclassified patients.

\section{Results}

Demographic characteristics, body mass indices, and GERD symptoms of the three comparison groups are presented in Table 1. Patients in the COL group were somewhat younger than the $\mathrm{BE}$ group (mean age, 57 years versus 63 years, $\mathrm{p}=0.02$ ). Although EGD patients had a significantly lower mean self-reported BMI than the $\mathrm{BE}$ group $\left(27 \mathrm{~kg} / \mathrm{m}^{2}\right.$ versus $\left.30 \mathrm{~kg} / \mathrm{m}^{2}\right)$, that in the COL group was not significantly different from the BE group. Not surprisingly, patients in the COL group were less likely to be male and white. $\mathrm{BE}$ patients were significantly more likely to report nocturnal regurgitation or nocturnal heartburn symptoms than either of the control groups (Table 1). In addition, BE patients reported more severe typical heartburn and regurgitation symptoms than either the EGD or COL groups (Figure 1A and 1B).

Univariate logistic regression evaluating factors associated with $\mathrm{BQ}+$ status revealed that $\mathrm{BE}$ was associated with an increased risk for OSA compared with COL controls but not EGD controls (Table 2). Within the BE group, $56 \%$ of patients scored at high risk for OSA on the Berlin Questionnaire $(\mathrm{n}=30)$. In comparison, $42 \%$ of EGD patients $(\mathrm{n}=26)$ were $\mathrm{BQ}+(\mathrm{OR} 1.73,95 \% \mathrm{CI}[0.83,3.62])$, and $37 \%$ of COL patients $(\mathrm{n}=64)$ were $\mathrm{BQ}+(\mathrm{OR} 2.08$, $95 \%$ CI $[1.12,3.88])$. On univariate logistic regression among the $\mathrm{BE}$ and $\mathrm{COL}$ groups combined, age but not gender or race was also associated with an increased risk for OSA. Obese BMI based on self report, which does contribute to one symptom category of the Berlin Questionnaire, was also associated with markedly increased risk for OSA. A multivariate logistic regression model adjusting for age (Table 3) revealed that the odds ratio for the association between $\mathrm{BE}$ and $\mathrm{BQ}+$ status was no longer significant at 1.84 ( $95 \%$ CI $0.98,3.47)$. Upon comparing the multivariate logistic regression model containing age and $\mathrm{BE}$ status with the nested model containing age alone, the multivariate model did not provide significantly better fit by the likelihood ratio test, although the p value was minimally greater than 0.05 (chi-square test $=3.55$, corresponding to a $\mathrm{p}$ value of 0.0595). Therefore, after adjusting for age, the association between $\mathrm{BE}$ and increased risk for OSA was no longer statistically significant. Likewise, a multivariate logistic regression model adjusting for age and BMI found no association between $\mathrm{BE}$ and $\mathrm{BQ}+$ status (Table 3 ).

Although the proportion of $B Q+$ patients was not significantly different between the $\mathrm{BE}$ and $\mathrm{EGD}$ groups, $\mathrm{BE}$ patients were more likely to score positively for 2 of the 3 symptom categories on the Berlin Questionnaire: snoring symptoms ( $56 \%$ for $\mathrm{BE}$ versus $32 \%$ for $\mathrm{EGD}, \mathrm{p}=0.01$ ) and the presence of obesity/HTN ( $74 \%$ for BE versus $48 \%$ for EGD, $p=0.005$ ). Figure 2 displays the proportion of subjects scoring positively for each symptom category of the Berlin Questionnaire among the 3 groups. However, within self-reported BMI strata (normal, overweight, or obese), there was no significant difference in snoring symptoms between the BE and EGD groups, suggesting that differences in BMI could explain the initial differences in snoring symptoms between the 2 groups. When $\mathrm{BE}$ patients were compared with the COL group, the proportion of subjects scoring positively for snoring symptoms or daytime somnolence did not differ significantly ( $56 \%$ for $\mathrm{BE}$ versus $45 \%$ for COL, $\mathrm{p}=0.18$ for snoring symptoms; $29 \%$ for $\mathrm{BE}$ versus $20 \%$ for COL, $\mathrm{p}=0.13$ for daytime somnolence/drowsiness while driving). $\mathrm{BE}$ patients were more likely to score positively for the $3^{\text {rd }} \mathrm{BQ}$ symptom category, presence of obesity/HTN, although this did not reach statistical significance ( $74 \%$ for $\mathrm{BE}$ versus $59 \%$ for COL, $\mathrm{p}=0.05$ ).

Because COL patients who were not getting upper endoscopy served as controls and could potentially have been misclassified, we performed a sensitivity analysis to evaluate the extent to which misclassification could have affected our results. A previous study of 961 colonoscopy patients undergoing upper endoscopy revealed that $6.8 \%$ 
Table 1 Demographic characteristics, mean body mass index, and GERD symptoms among 3 comparison groups

\begin{tabular}{llllll}
\hline & BE $(\mathbf{n}=\mathbf{5 4})$ & EGD $(\mathbf{n}=\mathbf{6 2})$ & P value (BE vs. EGD) & COL ( $\mathbf{n}=171)$ & P value (BE vs. COL) \\
\hline Mean age, years (SD) & $63(11.1)$ & $60(11.7)$ & NS & $57(13.6)$ & $0.001^{*}$ \\
White (\%) & $53(98.2)$ & $59(95.2)$ & NS & $70(41.9) \dagger$ & $<0.0001^{*}$ \\
Male (\%) & $38(70.4)$ & $36(58.1)$ & NS & $75(43.9)$ & $0.001^{\circ}$ \\
Mean BMl, kg/m ${ }^{2}$ (SD) & $30(5.9)$ & $27(5.5)$ & $0.03^{*}$ & $28(5.6)$ & $0.06^{*}$ \\
Heartburn symptoms (\%) & $43(79.6)$ & $33(53.2)$ & $0.003^{\circ}$ & $53(31.0)$ & $<0.0001^{\circ}$ \\
Nocturnal heartburn symptoms (\%) & $27(50.0)$ & $16(25.8)$ & $0.01^{\circ}$ & $21(12.3)$ & $<0.0001^{\circ}$ \\
Regurgitation symptoms (\%) & $42(77.7)$ & $38(61.3)$ & $0.06^{\circ}$ & $41(24.0)$ & $<0.0001^{\circ}$ \\
Nocturnal regurgitation symptoms (\%) & $31(57.4)$ & $18(29.0)$ & $0.002^{\circ}$ & $18(10.5)$ & $<0.0001^{\circ}$ \\
\hline
\end{tabular}

SD, Standard deviation

NS, Not significant

BMI, Body mass index

* Independent samples $t$ test with equal variances

- Chi-square test

†Among respondents; 4 subjects did not respond to the question about race.

${ }^{*}$ Fisher's exact test

had Barrett's esophagus; among colonoscopy patients with history of heartburn symptoms, $8.3 \%$ had Barrett's esophagus, compared with $5.6 \%$ among those with no history of heartburn symptoms [6]. We therefore assumed that 7\%, or 12, patients in the COL group in the current study could have been misclassified and actually had Barrett's esophagus. Assuming that the $\mathrm{BQ}+$ rate among these misclassified patients was 1 ) the same as that in the original $\mathrm{COL}$ group (a conservative estimate) versus 2 ) the $\mathrm{BQ}+$ rate in the original $\mathrm{BE}$ group, then the odds ratio would be 1.75 (95\% CI 0.98, 3.13) for the former scenario, versus 2.28 (95\% CI 1.27, 4.10) for the latter scenario. In all likelihood, the true odds ratio probably lies somewhere in between.

We explored the relationship between nocturnal GERD and $\mathrm{BQ}+$ status among all patients in the study, including cases and controls. Among all patients with nocturnal heartburn, the rate of $\mathrm{BQ}+$ was $58 \%(\mathrm{n}=37)$, compared with $37 \%(\mathrm{n}=83)$ among patients without nocturnal heartburn $(\mathrm{p}=0.003)$. Among all patients with nocturnal regurgitation, $63 \%$ were $B Q+(n=42)$, compared with $35 \%$ $(\mathrm{n}=78)$ among patients without nocturnal regurgitation $(\mathrm{p}<0.0001)$. We also examined the association between nocturnal GERD symptoms (defined as either nocturnal heartburn or regurgitation, or both) and scoring at high risk for OSA within each study group (Table 4). Within the $\mathrm{BE}$ and $\mathrm{COL}$ groups, $\mathrm{BQ}+$ subjects were more likely to report nocturnal GERD, although only $23 \%$ of $B Q+$ subjects reported nocturnal GERD in the COL group. There was no association between nocturnal GERD and BQ+ status within the EGD group.

\section{Discussion}

The majority of BE patients in our pilot study scored at high risk for OSA on the Berlin Questionnaire. After adjusting for age and BMI, the association between
Barrett's esophagus and scoring at high risk for OSA compared with the COL group was no longer statistically significant. Because older age and higher BMI are risk factors for OSA [30], these factors likely had a large effect on the study results because the $\mathrm{BE}$ group was older than the COL group and had a higher BMI than the EGD group. Patients with known OSA were excluded from our study; however, almost all of these patients came from the $\mathrm{BE}$ group which could have affected our results. In our study, $37 \%$ of COL patients scored at high risk for OSA, which is slightly greater than the $32 \%-36 \%$ rate previously described in primary care settings and a cardiology referral clinic $[26,29]$. Patients presenting for outpatient endoscopy at our hospital may be a higher risk population than patients in primary care settings, who in turn likely have a greater prevalence of OSA than the general population [31]. Nonetheless, the high rate of $\mathrm{BQ}+$ status among $\mathrm{BE}$ patients in our study is striking. Barrett's esophagus patients may be more likely to have obstructive sleep apnea than GERD patients without $\mathrm{BE}$ due to insulin/insulin growth factor pathways which may have a role in the development of $\mathrm{BE}$ [32]; obstructive sleep apnea is associated with insulin resistance [20]. Since our study was conducted, two other recent studies presented in abstract form have suggested that $\mathrm{BE}$ is associated with obstructive sleep apnea [33] or obstructive sleep apnea characteristics [34]. Taken together, these findings hold particular relevance because $\mathrm{BE}$ patients who undergo endoscopic surveillance or lengthier endoscopic ablative procedures may thereby be at increased risk for sedation-related complications. Benzodiazepines and opioids can depress respiratory drive, decrease upper airway reflexes, and decrease pharyngeal muscle tone $[35,36]$. Propofol can also lead to upper airway collapse $[35,37]$. These effects are particularly important for patients with obstructive sleep apnea due to redundant pharyngeal tissue and generally narrower airways [38]. 


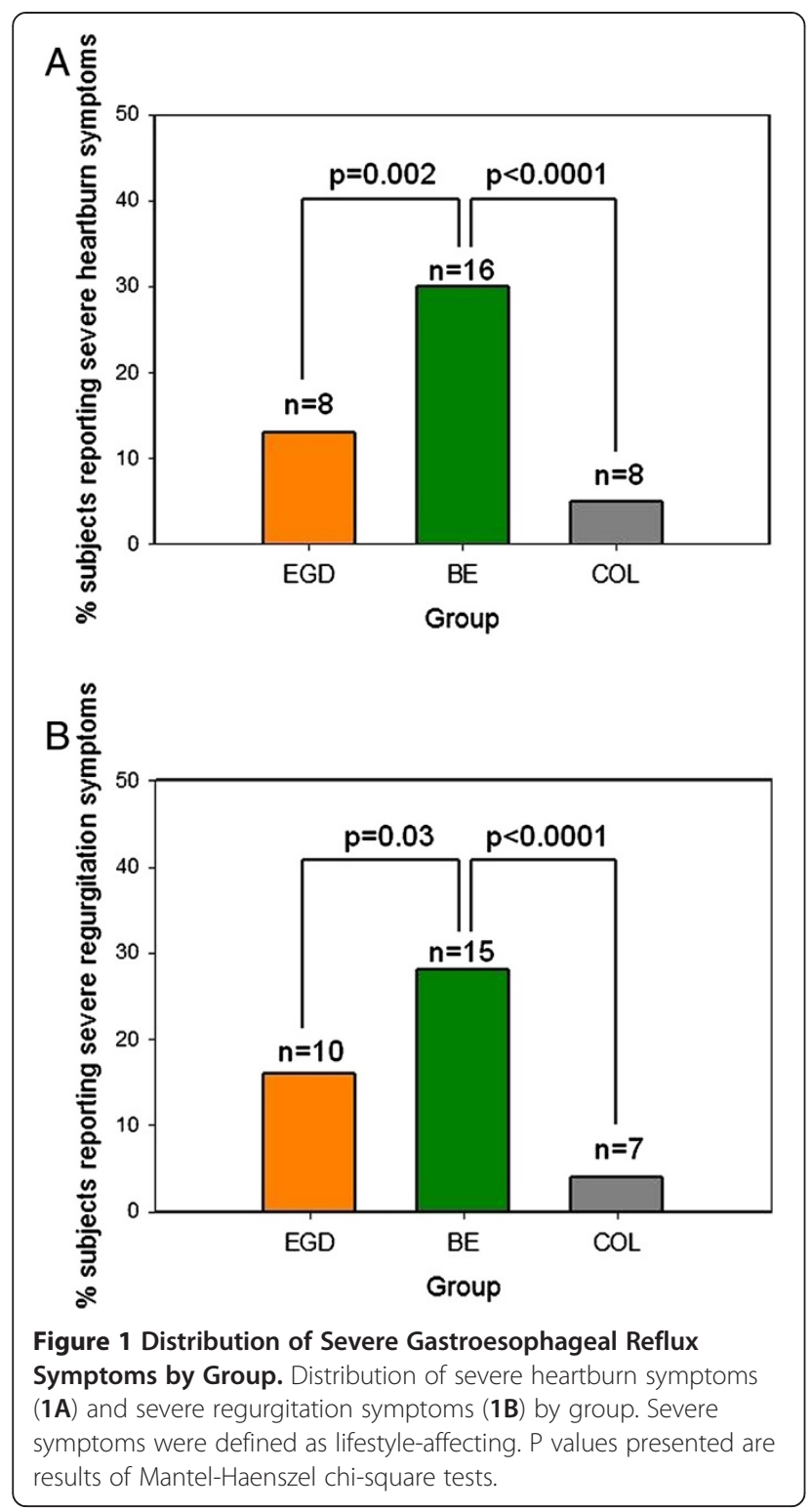

In the current study, $44 \%$ of EGD patients scored at high risk for OSA. This high rate is not surprising since many of these patients were likely undergoing EGD for GERD symptoms, and previous studies suggest that GERD is associated with sleep complaints $[15,16]$. In addition, Siupsinskiene and colleagues reported in abstract form results from a prospective Lithuanian study in which 42 OSA patients underwent upper endoscopy regardless of whether they had upper GI symptoms. This study revealed that $83.3 \%$ had pathologic GI findings: $64.3 \%$ had hiatal hernia, $45.2 \%$ had erosive esophagitis, and $21.4 \%$ had histological esophagitis [39]. There was no significant correlation between OSA severity and frequency of endoscopic findings. Although there was no mention of Barrett's esophagus as an endoscopic finding, BE presumably could have been masked by erosive esophagitis.
Table 2 Univariate analysis of factors associated with BQ+ status

\begin{tabular}{lll}
\hline & Odds ratio & $\mathbf{9 5 \%}$ Confidence interval \\
\hline BE vs. EGD group & 1.73 & $0.83,3.62$ \\
BE vs. COL group & 2.08 & $1.12,3.88$ \\
Among BE and COL groups: & & \\
$\quad$ Age & 1.03 & $1.004,1.047$ \\
Male gender & 1.32 & $0.78,2.25$ \\
White race (vs. non-white) & 1.11 & $0.65,1.90$ \\
BMl & & \\
$\quad$ Normal & 1.0 & \\
$\quad$ Overweight & 2.37 & $1.03,5.46$ \\
$\quad$ Obese & 16.8 & $7.30,38.76$ \\
\hline
\end{tabular}

In our study, BE patients were more likely than either of the control groups to report nocturnal heartburn or nocturnal regurgitation. BE patients also reported more severe typical GERD symptoms than patients in either control group. These findings are consistent with previous studies demonstrating higher esophageal acid exposure in BE patients $[40,41]$. Within the BE and COL groups, nocturnal GERD was associated with $\mathrm{BQ}+$ status, although the rate of nocturnal GERD was low (23\%) among BQ+ subjects in the COL group. These findings raise questions of whether $\mathrm{BE}$ could be associated with obstructive sleep apnea through a higher incidence of nocturnal GERD or whether nocturnal GERD itself increases the risk of obstructive sleep apnea. Previous studies have been inconsistent in demonstrating a link between nocturnal GERD and BE [21-24,42]. The relationship between GERD and OSA is incompletely understood. Nocturnal GERD was associated with sleep complaints [16] or OSA symptoms [43] in large cohort studies, and continuous positive airway pressure improved GERD symptoms in OSA patients $[17,18]$.

Table 3 Multivariate analysis of factors associated with $\mathrm{BQ}+$ status among $\mathrm{BE}$ and $\mathrm{COL}$ groups

\begin{tabular}{cll}
\hline & Odds ratio & $\begin{array}{l}\mathbf{9 5 \%} \text { Confidence } \\
\text { interval }\end{array}$ \\
\hline Model containing age and BE status & 1.73 & $0.83,3.62$ \\
Age & 1.02 & $1.00,1.04$ \\
BE & 1.84 & $0.98,3.47$
\end{tabular}

Model containing age, BE status, and BMI

\begin{tabular}{lll} 
Age & 1.03 & $1.00,1.05$ \\
BE & 1.51 & $0.72,3.15$ \\
BMI & & \\
$\quad$ Normal & 1.0 & \\
Overweight & 2.32 & $0.99,5.43$ \\
$\quad$ Obese & 16.77 & $7.1,39.42$ \\
\hline
\end{tabular}




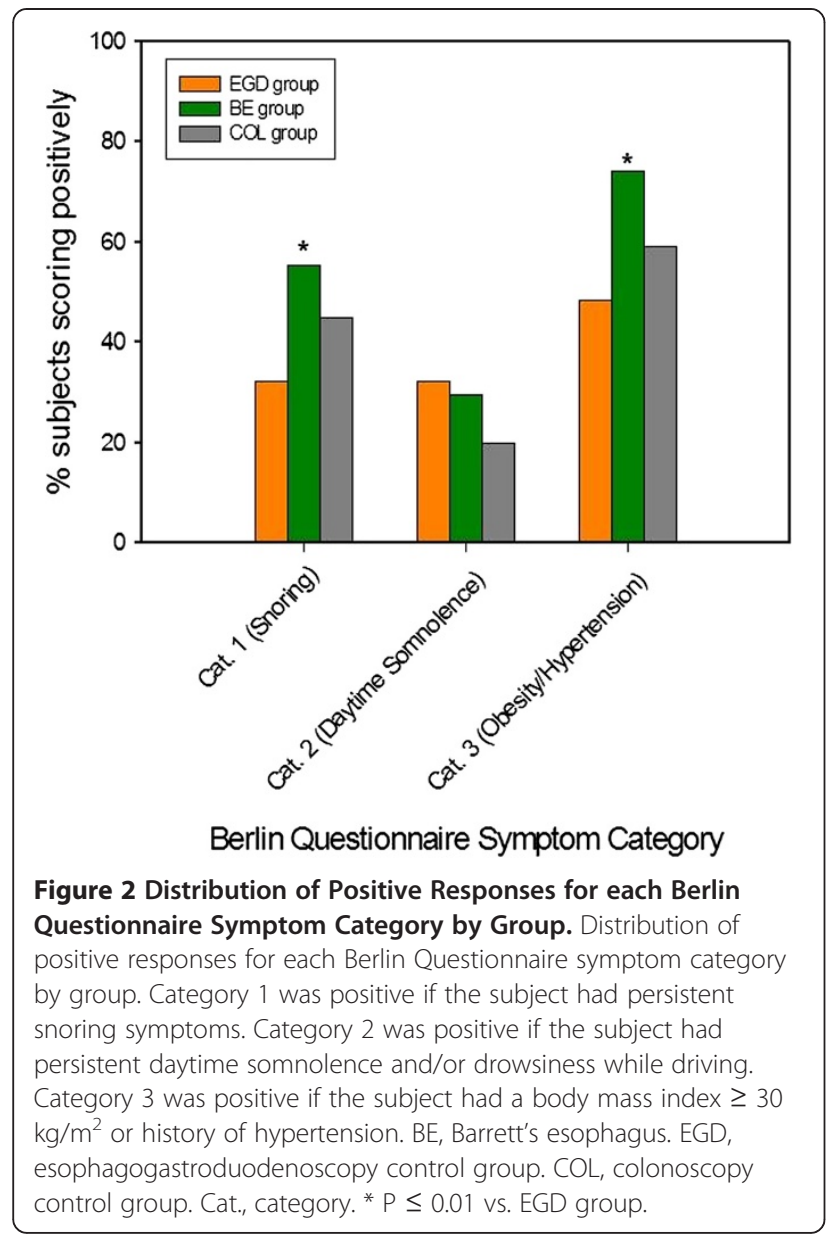

However, a recent small study suggested no difference in the number of nocturnal gastroesophageal reflux events as measured by $\mathrm{pH}$ monitoring and impedance among OSA patients without GERD, OSA patients with GERD, GERD patients without OSA, and healthy controls [44]. In addition, high-resolution manometry measurements in that study suggested that during OSA events, gastroesophageal junction and upper esophageal sphincter pressures actually increased-changes which would be expected to prevent rather than induce reflux events.

Our pilot study had several limitations. Our study was limited by the use of open-access colonoscopy patients who were not getting EGD as controls, since we assumed that those patients did not have Barrett's esophagus. The decision to include the COL control group in our study was partially due to slow accrual of EGD controls. Based on our sensitivity analysis, misclassification could have potentially strengthened or weakened an association between $\mathrm{BE}$ and $\mathrm{BQ}+$ status. In addition, the study was limited due to exclusion of patients with known OSA; since most of these patients had Barrett's esophagus, this could have affected the study results. Our study was also limited because results of the Berlin Questionnaire were not confirmed with polysomnography. Previous validation of the Berlin Questionnaire in a surgical patient population demonstrated a sensitivity of $68.9 \%-87.2 \%$ at various apnea-hypopnea index cutoffs [28]. Our assessment of nocturnal GERD was based on patient self-assessment of symptoms rather than an objective measure such as esophageal pH monitoring. The Berlin Questionnaire is partially based on self-reported BMI, which can vary significantly and unpredictably from the true BMI value and can potentially be misleading in very muscular patients. Finally, a type II error might explain why the association between $\mathrm{BE}$ and $\mathrm{BQ}+$ status disappeared after adjusting for age.

\section{Conclusions}

In summary, the findings from this pilot study demonstrate that a high proportion of Barrett's esophagus patients score at high risk for obstructive sleep apnea. This finding is particularly important because many BE patients undergo endoscopic surveillance, and a minority undergo lengthier endoscopic procedures for ablation of dysplasia. $\mathrm{BE}$ patients may therefore be periodically exposed to sedation with its inherent risks. Given the high proportion of $\mathrm{BE}$ subjects at high risk for OSA in our study, screening for OSA should be considered in BE patients. At the very least, raising awareness that $\mathrm{BE}$ patients are likely to score at high risk for OSA may facilitate the judicious use of opioids and sedatives, consideration for use of capnography during sedation for lengthier endoscopic ablative procedures, and more vigilant post-procedure monitoring in $\mathrm{BE}$ patients undergoing surveillance endoscopy. Our results also demonstrated that patients scoring at high risk for obstructive sleep apnea were more likely to report nocturnal heartburn or acid regurgitation symptoms. Our findings support a growing body of literature linking nocturnal GERD to sleep disturbances. Future studies could explore mechanistic links among Barrett's esophagus, nocturnal GERD, and obstructive sleep apnea.

Table $4 \mathrm{BQ}+$ status within each study group by nocturnal GERD symptoms

\begin{tabular}{|c|c|c|c|c|c|c|}
\hline & \multicolumn{2}{|c|}{ BE group $(n=54)$} & \multicolumn{2}{|c|}{ EGD group $(n=62)$} & \multicolumn{2}{|c|}{$\operatorname{COL}$ group $(n=171)$} \\
\hline & nGER+ $(n=34)$ & nGER- $(n=20)$ & nGER+ $(n=21)$ & nGER-(n = 41) & nGER+ $(n=26)$ & nGER- $(n=145)$ \\
\hline $\mathrm{BQ}+(\%)$ & $23^{*}(67.6)$ & $7(35.0)$ & $10(47.6)$ & $16(39.0)$ & $15^{*}(57.7)$ & 49 (33.8) \\
\hline
\end{tabular}

nGER, nocturnal gastroesophageal reflux symptoms (heartburn or regurgitation)

${ }^{*} \mathrm{p}=0.02$ by chi-square test comparing nocturnal GERD symptoms within study group 


\section{Abbreviations}

EAC: Esophageal adenocarcinoma; BE: Barrett's esophagus; GERD: Gastroesophageal reflux disease; OSA: Obstructive sleep apnea; EGD group: Esophagogastroduodenoscopy control group; COL group: Colonoscopy control group; RDI: Respiratory disturbance index; $\mathrm{BQ}$ : Berlin Questionnaire.

\section{Competing interests}

The authors declare that they have no competing interests.

\section{Authors' contributions}

LCC participated in the study design, acquisition of data, data analysis, interpretation of results, and manuscript writing. NS, SM, WS, and VK participated in acquisition of data and editing the manuscript. AC conceived of the study and participated in the study design, acquisition of data, interpretation of results, and editing the manuscript. All authors read and approved the final manuscript.

\section{Acknowledgements}

We are indebted to Susan Redline, MD, MPH, and Sanjay Patel, MD, MS, for expertise provided in sleep-disordered breathing for this project. This study was funded in part by Respironics Sleep and Respiratory Research Foundation (SPC106642) to AC and support from the Division of Gastroenterology and Liver Disease, University Hospitals Case Medical Center. LCC was supported by an NIH Postdoctoral Training Grant in Digestive Diseases (T32-DK61917), NIH Paul Calabresi Award for Clinical Oncology (K12 CA076917), and Case SPORE in Gl Malignancies (P50 CA150964). AC was supported by a Midcareer Award in Patient Oriented Research (K24DK002800) from the NIDDK.

\section{Author details}

'Division of Gastroenterology and Liver Disease, Department of Medicine, University Hospitals Case Medical Center, 1100 Euclid Avenue Mailstop 5066, Cleveland, OH 44106-5066, USA. ²Gastroenterology Associates, 1400 N Ritter Avenue Suite 370, Indianapolis, IN 46219, USA. ${ }^{3}$ Mayo Clinic Jacksonville, 4500 San Pablo Road, Jacksonville, FL 32224, USA. ${ }^{4}$ University of Illinois at Chicago, Section of Digestive Diseases and Nutrition, 840 South Wood Street (MC716), Chicago, IL 60612, USA.

Received: 5 July 2012 Accepted: 3 May 2013

Published: 11 May 2013

\section{References}

1. Devesa SS, Blot WJ, Fraumeni FJ Jr: Changing patterns in the incidence of esophageal and gastric carcinoma in the United States. Cancer 1998, 83:2049-2053.

2. Pohl H, Sirovich B, Welch HG: Esophageal Adenocarcinoma Incidence: Are We Reaching the Peak? Cancer Epidemiol Biomarkers Prev 2010, 19:1468-1470.

3. Lagergren J, Bergstrom R, Lindgren A, Nyren O: Symptomatic gastroesophageal reflux as a risk factor for esophageal adenocarcinoma. N Engl J Med 1999, 340:825-831.

4. American Gastroenterological Association medical position statement on the management of Barrett's esophagus. Gastroenterology 2011, 140:1084-1091.

5. Westhoff B, Brotze S, Weston A, McElhinney C, Cherian R, Mayo MS, Smith HJ, Sharma P: The frequency of Barrett's esophagus in high-risk patients with chronic GERD. Gastrointest Endosc 2005, 61:226-231.

6. Rex DK, Cummings OW, Shaw M, Cumings MD, Wong RKH, Vasudeva RS, Dunne D, Rahmani EY, Helper DJ: Screening for Barrett's esophagus in colonoscopy patients with and without heartburn. Gastroenterology 2003, 125:1670-1677.

7. Ronkainen J, Aro P, Storskrubb T, Johansson S-E, Lind T, Bolling-Sternevald E, Vieth M, Stolte M, Talley NJ, Agreus L: Prevalence of Barrett's esophagus in the general population: an endoscopic study. Gastroenterology 2005 129:1825-1831.

8. Frazzoni $M$, Micheli ED, Savarino $V$ : Different patterns of oesophageal acid exposure distinguish complicated reflux disease from either erosive reflux esophagitis or non-erosive reflux disease. Aliment Pharmacol Ther 2003, 18:1091-1098
9. Hampel H, Abraham NS, El-Serag HB: Meta-Analysis: Obesity and the risk for gastroesophageal reflux disease and its complications. Ann Intern Med 2005, 143:199-211.

10. Caygill CPJ, Johnston DA, Lopez M, Johnston BJ, Watson A, Reed PI, Hill MJ: Lifestyle factors and Barrett's esophagus. Am J Gastroenterol 2002, 97:1328-1331.

11. El-Serag HB, Kvapil P, Hacken-Bitar J, Kramer JR: Abdominal obesity and the risk of Barrett's esophagus. Am J Gastroenterol 2005, 100:2151-2156.

12. Ing AJ, Ngu MC, Breslin ABX: Obstructive sleep apnea and gastroesophageal reflux. Am J Med 2000, 108:120S-125S.

13. Shepherd KL, James AL, Musk AW, Hunter ML, Hillman DR, Eastwood PR: Gastro-oesophageal reflux symptoms are related to the presence and severity of obstructive sleep apnoea. J Sleep Res 2011, 20:241-249.

14. Shepherd K, Hillman D, Holloway R, Eastwood P: Mechanisms of nocturnal gastroesophageal reflux events in obstructive sleep apnea. Sleep Breath 2011, 15:561-570.

15. Gislason T, Janson C, Vermeire P, Plaschke P, Bjornsson E, Gislason D, Boman $G$ : Respiratory symptoms and nocturnal gastroesophageal reflux: $a$ population-based study of young adults in three European countries. Chest 2002, 121:158-163.

16. Fass R, Quan SF, O'Connor GT, Envin A, Iber C: Predictors of heartburn during sleep in a large prospective cohort study. Chest 2005, 127:1658-1666.

17. Green BT, Broughton WA, O'Connor B: Marked improvement in nocturnal gastroesophageal reflux in a large cohort of patients with obstructive sleep apnea treated with continuous positive airway pressure. Arch Intern Med 2003, 163:41-45.

18. Tawk M, Goodrich S, Kinasewitz G, Orr W: The effect of 1 week of continuous positive airway pressure treatment in obstructive sleep apnea patients with concomitant gastroesophageal reflux. Chest 2006, 130:1003-1008.

19. Ntalapascha M, Makris D, Kyparos A, Tsilioni I, Kostikas K, Gourgoulianis K, Kouretas D, Zakynthinos E: Oxidative stress in patients with obstructive sleep apnea syndrome. Sleep Breath 2012:1-7. Epub ahead of print.

20. Ip MSM, Lam B, Ng MMT, Lam WK, Tsang KWT, Lam KSL: Obstructive Sleep Apnea Is Independently Associated with Insulin Resistance. Am J Respir Crit Care Med 2002, 165:670-676.

21. Eloubeidi MA, Provenzale D: Clinical and Demographic Predictors of Barrett's Esophagus Among Patients With Gastroesophageal Reflux Disease: A Multivariable Analysis in Veterans. J Clin Gastroenterol 2001, 33:306-309.

22. Gaddam S, Maddur H, Wani S, Gupta N, Singh M, Singh V, Moloney B, Puli SR, Rastogi A, Bansal A, Sharma P: Risk Factors for Nocturnal Reflux in a Large GERD Cohort. J Clin Gastroenterol 2011, 45:764-768.

23. Fouad Y, Makhlouf M, Tawfik H, El Amin H, Abdel Ghany W, El-Khayat H: Barretts esophagus: Prevalence and risk factors in patients with chronic GERD in Upper Egypt. World J Gastroenterol 2009, 15:3511-3515.

24. Gutschow C, Bludau M, Vallböhmer D, Schröder W, Bollschweiler E, Hölscher A: NERD, GERD, and Barrett's Esophagus: Role of Acid and Non-acid Reflux Revisited with Combined pH-Impedance Monitoring. Dig Dis Sci 2008, 53:3076-3081.

25. Netzer NC, Stoohs RA, Netzer CM, Clark K, Strohl KP: Using the Berlin Questionnaire to identify patients at risk for the sleep apnea syndrome. Ann Intern Med 1999, 131:485-491.

26. Netzer NC, Hoegel JJ, Loube D, Netzer CM, Hay B, Alvarez-Sala R, Strohl KP. Prevalence of symptoms and risk of sleep apnea in primary care. Chest 2003, 124:1406-1414

27. Khiani VS, Salah W, Maimone S, Cummings L, Chak A: Sedation during endoscopy for patients at risk of obstructive sleep apnea. Gastrointest Endosc 2009, 70:1116-1120

28. Chung F, Yegneswaran B, Liao P, Chung SA, Vairavanathan S, Islam S, Khajehdehi A, Shapiro CM: Validation of the Berlin questionnaire and American Society of Anesthesiologists checklist as screening tools for obstructive sleep apnea in surgical patients. Anesthesiology 2008, 108:822-830.

29. Gami AS, Pressman G, Caples SM, Kanagala R, Gard JJ, Davison DE, Malouf $J$ J, Ammash NM, Friedman PA, Somers VK: Association of atrial fibrillation and obstructive sleep apnea. Circulation 2004, 110:364-367.

30. Young T, Skatrud J, Peppard PE: Risk factors for obstructive sleep apnea in adults. JAMA 2004, 291:2013-2016.

31. Dement $W$, Netzer N: Primary care: is it the setting to address sleep disorders? Sleep Breath 2000, 4:1-9. 
32. Greer KB, Thompson CL, Brenner L, Bednarchik B, Dawson D, Willis J, Grady WM, Falk GW, Cooper GS, Li L, Chak A: Association of insulin and insulin-like growth factors with Barrett's oesophagus. Gut 2012, 61:665-672.

33. Leggett C, Calvin AD, Gorospe EC, Penfield JD, Somers VK, Caples S, Bungum A, Wang KK, David A, Katzka DA, Prasad GA: Obstructive sleep apnea is a risk factor for Barrett's esophagus. Gastroenterology 2012, 142:S751-S752.

34. Hannallah M, Exeter Y, Gillespie M, Hoefling J: The prevalence of obstructive sleep apnea characteristics in patients with Barrett's esophagus. In American Society of Anesthesiologists Annual Meeting. Washington, DC; 2012

35. Norton J, Ward D, Karan S, Voter W, Palmer L, Varlese A, Rackovsky O, Bailey $P$ : Differences between midazolam and propofol sedation on upper airway collapsibility using dynamic negative airway pressure. Anesthesiology 2006, 104:1155-1164.

36. Tagaito $\mathrm{Y}$, Isono $\mathrm{S}$, Nishino $\mathrm{T}$ : Upper airway reflexes during a combination of propofol and fentanyl anesthesia. Anesthesiology 1998, 88:1459-1466.

37. Eastwood P, Platt P, Shepherd K, Madison K, Hillman D: Collapsibility of the upper airway at different concentrations of propofol anesthesia. Anesthesiology 2005, 103:470-477.

38. Hillman D, Platt P, Eastwood P: The upper airway during anaesthesia. Br J Anaesth 2003, 91:31-39.

39. Siupsinskiene N, Adamonis K, Toohill R: Gastrointestinal findings in obstructive sleep apnea patient. Otolaryngol Head Neck Surg 2009, 141:P227-P228

40. Dickman R, Parthasarathy S, Malagon IB, Jones P, Han B, Powers J, Fass R: Comparisons of the distribution of oesophageal acid exposure throughout the sleep period among the different gastro-oesophageal reflux disease groups. Aliment Pharmacol Ther 2007, 26:41-48.

41. Shapiro M, Green C, Faybush EM, Esquivel RF, Fass R: The extent of oesophageal acid exposure overlap among the different gastro-oesophageal reflux disease groups. Aliment Pharmacol Ther 2006, 23:321-329.

42. Gerson LB, Edson R, Lavori PW, Triadafilopoulos G: Use of a simple symptom questionnaire to predict Barrett's esophagus in patients with symptoms of gastroesophageal reflux. Am J Gastroenterol 2001, 96:2005-2012.

43. Emilsson Öl, Janson C, Benediktsdóttir B, Júlíusson S, Gíslason T: Nocturnal gastroesophageal reflux, lung function and symptoms of obstructive sleep apnea: Results from an epidemiological survey. Respir Med 2012 106:459-466.

44. Kuribayashi S, Massey BT, Hafeezullah M, Perera L, Hussaini SQ, Tatro L, Darling RJ, Franco R, Shaker R: Upper esophageal sphincter and gastroesophageal junction pressure changes act to prevent gastroesophageal and esophagopharyngeal reflux during apneic episodes in patients with obstructive sleep apnea. Chest 2010, 137:769-776.

doi:10.1186/1471-230X-13-82

Cite this article as: Cummings et al.: Barrett's esophagus and the risk of obstructive sleep apnea: a case-control study. BMC Gastroenterology 2013 13.82

\section{Submit your next manuscript to BioMed Central and take full advantage of:}

- Convenient online submission

- Thorough peer review

- No space constraints or color figure charges

- Immediate publication on acceptance

- Inclusion in PubMed, CAS, Scopus and Google Scholar

- Research which is freely available for redistribution 